\title{
TLAČNO ISPITIVANJE KAPITELA STUPA IZ PALAČE MOISE U CRESU
}

\section{COMPRESSION TEST OF A COLUMN CAPITAL OF MOISE PALACE IN CRES}

\author{
Željko Smolčić*, Paulo Šćulac
}

\begin{abstract}
Sažetak
U radu je prikazano tlačno ispitivanje kapitela stupa iz palače Moise u Cresu, starog oko 500 godina. Pri sanaciji palače, na kapitelu stupa primijećena su vidljiva oštećenja čiji uzrok nije poznat. Zbog oštećenja na kapitelu stupa bilo je neophodno provesti tlačno ispitivanje do predviđenog uporabnog opterećenja. Cilj rada je ukazati na neophodnost suradnje izvođača, projektanta, konzervatora $i$ korištenja laboratorijskih ispitivanja kod dokaza nosivosti $i$ uporabljivosti konstrukcijskih elemenata. Rezultati tlačnog ispitivanja pokazali su da kapitel stupa može podnijeti predviđeno uporabno opterećenje.
\end{abstract}

Ključne riječi: kapitel stupa, oštećenje, pukotina, tlak, laboratorijsko ispitivanje

\begin{abstract}
The paper describes compression test of a column capital, about 500 years old, from the Moise palace in Cres. In the repair of the palace on the column capital, visible damage of unknown origin has been noticed. Due to the damage on the column capital, it was necessary to conduct the compression test to the prescribed service load. The aim of this paper is to demonstrate the need for cooperation between contractors, structural designers, conservators and use of laboratory testing for proof of bearing capacity and serviceability of structural elements. The results of compression test have shown that the column capital can withstand the expected service load.
\end{abstract}

Key words: column capital, damage, crack, compression, laboratory test

\footnotetext{
* Sveučilište u Rijeci, Građevinski fakultet, Radmile Matejčić 3, 51000 Rijeka

E-mail: \{zeljko.smolcic,paulo.sculac\}@uniri.hr
} 


\section{Uvod}

Kod tradicijskih građevina često susrećemo stupove sastavljene od tijela, baze i kapitela. Svi elementi stupa su izrađeni od jednog komada kamena i najčešće su međusobno povezani željeznim trnom. Trnovi su položeni u otvore nešto većeg promjera i naknadno su ispunjeni olovom [1].

Zbog nejednolikog slijeganja temelja, imperfekcija kod izvedbe, potresa, preraspodjele naprezanja u svodovima, temperaturnih promjena $\mathrm{i}$ sanacijskih zahvata, tijekom povijesti građevina dolazi do ekscentričnog opterećenja stupova, kao i do otklona stupova od uspravne osi. Posljedica gore navedenih razloga je ekscentrično opterećenje stupova i zaokret spojnih elemenata stupa, odnosno otvaranje spoja $s$ jedne i nalijeganje spojnih ploha na drugu stranu presjeka. Zbog male površine nalijeganja (tlačna zona) dolazi do koncentracije tlačnih naprezanja koja dovode do otvaranja karakterističnih pukotina u blizini kontakata. Problem pojave pukotina u tradicijskim stupovima i način sanacije stupova analiziran je u nekoliko domaćih znanstvenih članaka $[1,2,3]$.

Veliki kompleks palače Moise jedan je od najmonumentalnijih creskih objekata 16. stoljeća [4]. Palača Moise bila je u lošem stanju do kojeg je dovelo dugogodišnje neodržavanje. Projekt sanacije, adaptacije i prenamjene palače Moise provodi se od 2003. godine. Tijekom sanacije stupova u atriju palače uočena su oštećenja na kapitelu stupa te je projektant predložio da se provede tlačno laboratorijsko ispitivanje do predviđene veličine uporabnog opterećenja.

Cilj rada je prikazati neophodnost suradnje izvođača, projektanta, konzervatora i korištenje laboratorijskih ispitivanja kod dokaza nosivosti i uporabljivosti konstrukcijskih elemenata. Za ispitivanja konstrukcijskih elemenata povijesnih kamenih građevina ne postoje normama propisane metode ispitivanja. Zbog specifičnosti povijesnih kamenih građevina neophodna je koordinirana suradnja širokog kruga stručnjaka u detekciji problema, analizi postojećeg stanja, provedbi laboratorijskog ispitivanja, interpretaciji rezultata ispitivanja i preporukama za ugradnju elemenata $u$ buduću konstrukciju. Osim toga, ukratko je opisana korištena laboratorijska oprema koja je nabavljena projektom RISK [5].

\section{Kapitel stupa prije ispitivanja}

Patricijska kuća obitelji Moise najveća je renesansna kuća u Cresu iz 16. stoljeća pa je domaći stanovnici nazivaju palačom. Građena je prema venecijanskom modelu s lokalnim specifičnostima. Projekt obnove započeo je još 2003. godine upisom zgrade na Listu prioritetnih intervencija. Pripremni radovi za obnovu otvoreni su 2008. godine, a 2010. godine je 
potpisan sporazum o namjeni građevine između Grada Cresa i Sveučilišta u Rijeci. Dogovoreno je da će se u Palači Moise smjestiti sveučilišni istraživački centar i centar za cjeloživotno učenje $s$ nizom sadržaja (učionice, uredi, polivalentna dvorana, dormitorij za studente, profesorski apartmani, restoran, knjižnica i izložbeni prostor). Prilikom obnove otkriveno je i nekoliko stupova s kapitelima te monofore za koje je odlučeno da će se sačuvati i uklopiti u konačni izgled zgrade [6].

Pri sanaciji stupova u palači Moise uočena su oštećenja i pukotine na kapitelu stupa. Uzrok vidljivog oštećenja kapitela stupa nije poznat, budući da u trenutku kada stup još uvijek nije bio demontiran nije bilo vidljivih metalnih spojnih elemenata (Slika 1.). Budući da pukotine sežu po gotovo cijeloj visini kapitela, a na donjem dijelu stupa nije bilo oštećenja, vjerojatno se ne radi o uobičajenom problemu korodiranja trna na spoju dijelova stupa. Također, nije moguće utvrditi dubinu pukotine. Bilo je nemoguće utvrditi je li se radilo o površinskom oštećenju ili ono seže dublje kroz širinu kapitela.

Ukoliko bi do sloma kamenog kapitela došlo nakon sanacije, šteta bi bila velika jer bi istovremeno moglo doći do pomaka čelične (i staklene) konstrukcije nad njim, a zamjena kapitela nakon što je konstrukcija nad njim već izvedena bila bi iznimno složena.

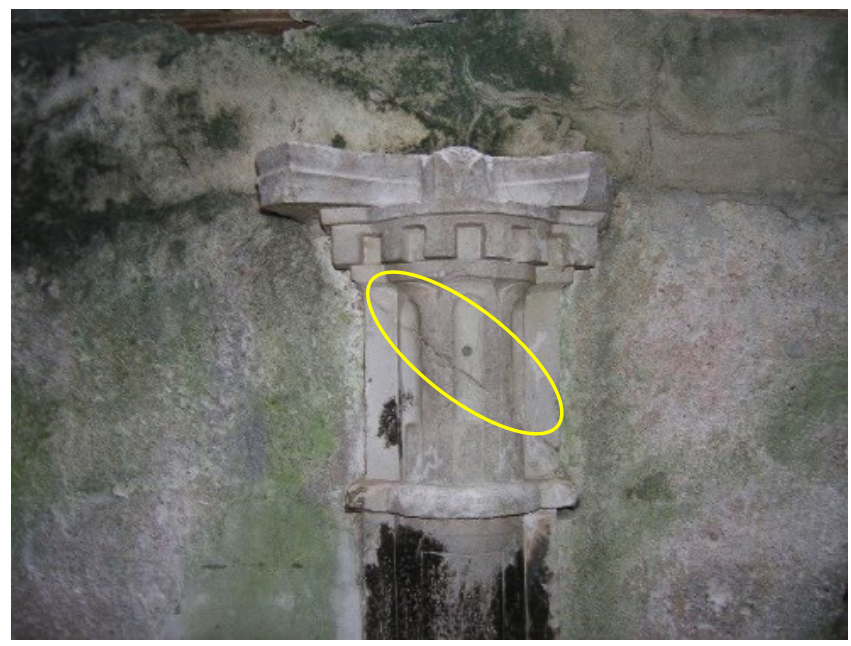

Slika 1. Kapitel stupa s označenom pukotinom

Zbog navedenih razloga projektant je predložio da se provede tlačno ispitivanje kapitela stupa. Bitno je naglasiti da se laboratorijskim ispitivanjem ne bi utvrđivala konačna vrijednost tlačne čvrstoće kamena povećavanjem tlačne sile do sloma elementa. Kapitel stupa bi se opteretio (preko čelične grede koja će biti prema projektu i ugrađena na njega) silom u iznosu od $50 \mathrm{kN}$ (u što su uključeni i faktori sigurnosti) pod predviđenim uporabnim opterećenjem poda prvog kata, težinom staklene stijene i 
propisanim opterećenjem krovne konstrukcije koja se također dijelom oslanja na stup.

Pri opisanom opterećenju kontrolirala bi se eventualna promjena širine postojeće pukotine i dolazi li do pojave novih oštećenja na elementu koja sugeriraju da je došlo do prekoračenja tlačne čvrstoće. Nije moguće predvidjeti hoće li do oštećenja doći i na koji način će se ona manifestirati. Tlačno ispitivanje potrebno je zaustaviti kod eventualne pojave prvih oštećenja ili veće vrijednosti širenja postojeće pukotine. Ne bude li pojave novih pukotina ili širenja postojećih pukotina, ispitivanje će se provoditi do tlačne sile od $50 \mathrm{kN}$. Važnost zaustavljanja ispitivanja, u slučaju širenja pukotina, bitna je kako bi kapitel stupa ostao u maksimalno očuvanom stanju radi izrade replike.

\section{Korištena laboratorijska oprema}

\subsection{Univerzalni tlačno-vlačni stroj za ispitivanje (kidalica)}

Univerzalni tlačno-vlačni stroj za ispitivanje (kidalica) Zwick Z $600 E$ (Slika 2.) je kapaciteta $600 \mathrm{kN}$ i pokretan je elektromotorom. Glavna namjena kidalice je monotono statičko ispitivanje, a osim toga su moguća i niskociklička ispitivanja do $0,5 \mathrm{~Hz}$. Ispitivanja na kidalici moguće je raditi uz kontrolu sile, kontrolu pomaka i kontrolu deformacije (ekstenzometar). Brzine ispitivanja pri kontroli pomaka su od 0,001 do $320 \mathrm{~mm} / \mathrm{min}$. Kidalica je koncipirana tako da ima dva radna prostora. Gornji radni prostor primarno je namijenjen za vlačna ispitivanja, dok je donji radni prostor namijenjen za tlačna ispitivanja i ispitivanja na savijanje. Za prihvat uzoraka postoje hidraulične čeljusti (600 kN), pneumatske čeljusti $(10 \mathrm{kN})$ i mehaničke čeljusti $(10 \mathrm{kN})$. Uz kidalicu, nabavljeni su alati i umetci za ispitivanje okruglih i pravokutnih uzoraka čelika, ispitivanje drva i ispitivanje plastike [5, 7]. Strojem upravlja računalo programom testXpert II $[5,7]$ kojim se mogu vršiti ispitivanja prema raznim standardima (ISO, EN, DIN ASTM i sl.) [5, 7]. Kidalica posjeduje i temperaturnu komoru u kojoj se mogu vršiti ispitivanja od $-80^{\circ} \mathrm{C}$ do $250^{\circ} \mathrm{C}$ uz pomoć mehaničkih čeljusti $(10$ $\mathrm{kN})[5,7]$. 


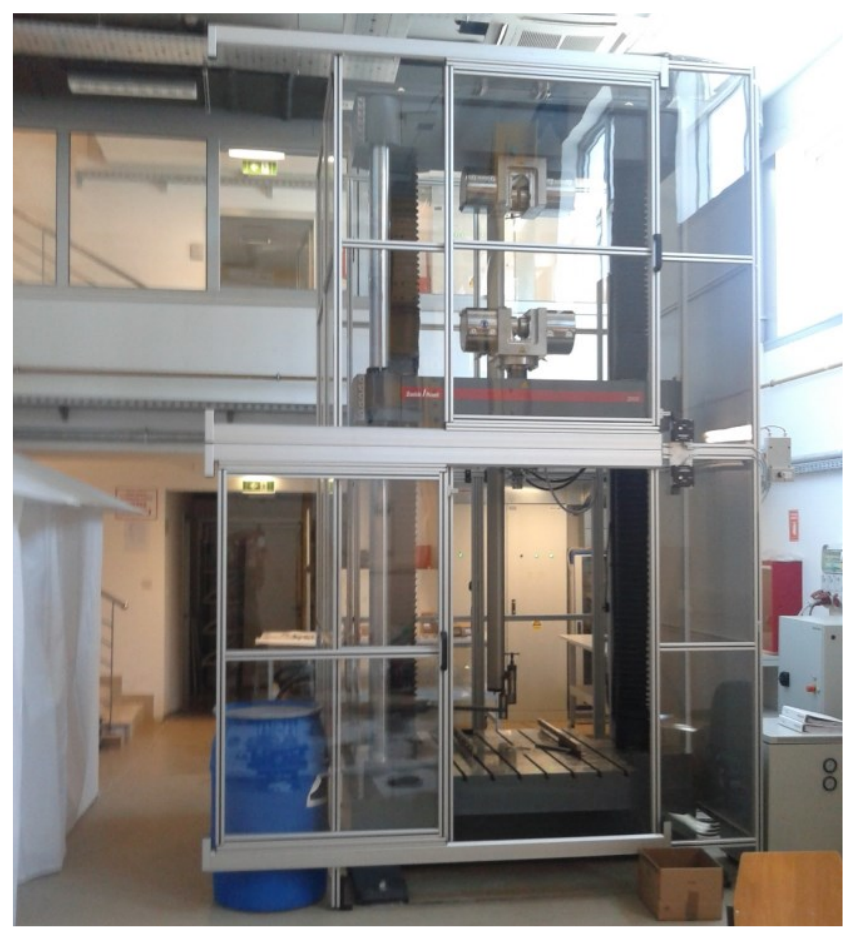

Slika 2. Univerzalni tlačno-vlačni stroj za ispitivanje (kidalica)

\subsection{Oprema za mjerenje pomaka}

Za mjerenje promjene širine pukotine korišten je linearni varijabilni diferencijalni transformator (LVDT) s mjernim rasponom $\pm 5 \mathrm{~mm}$ (Slika 3.), te uređaj za pripremu ulaznog signala i prikupljanje podataka NI SCXI-1540 proizvođača National Instruments. NI SCXI-1540 je jedan od modula SCXI platforme za kondicioniranje signala namijenjen za senzore koji se temelje na pretvaranju pomaka u električne signale, poput linearnog ili rotacijskog varijabilnog diferencijalnog transformatora (prvi se koristi za mjerenje pravocrtnih, a drugi za kutne pomake) [7].

LVDT pripada kategoriji senzora za precizno mjerenje pomaka. Sastoji se od primarne zavojnice, dvije sekundarne zavojnice (postavljene simetrično oko primarne zavojnice) te pomične jezgre, smještene u cilindrično kućište. Primarna zavojnica napaja se izmjeničnom strujom, a uslijed pomicanja jezgre dolazi do promjene napona između sekundarnih zavojnica, a ta se razlika napona koristi za određivanje vrijednosti pomaka [8]. Prikupljanje i obrada izmjerenih podataka provedena je pomoću programskog softvera NI SignalExpress [9]. 


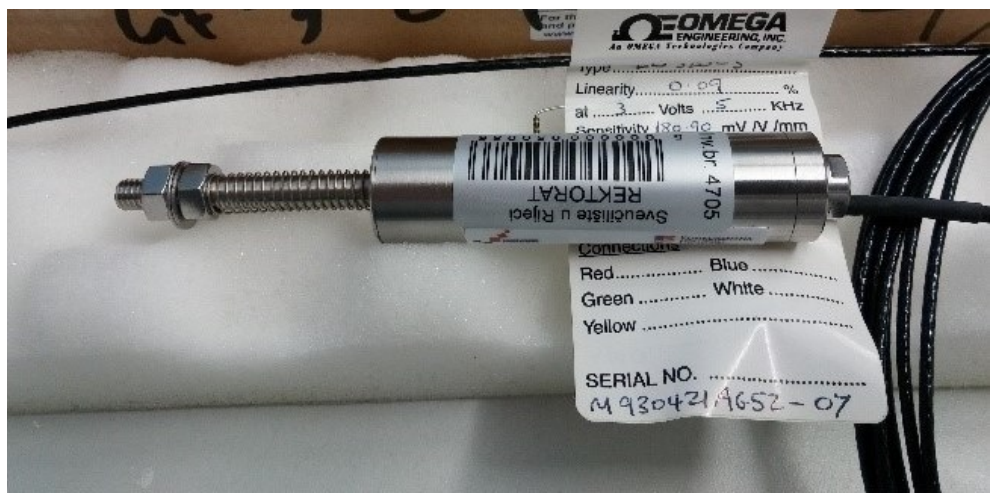

Slika 3. AC LVDT s nominalnim hodom $\pm 5 \mathrm{~mm}$

\section{Tlačno ispitivanja kapitela stupa}

Zbog stanja kapitela stupa posebna se pažnja posvetila transportu kapitela stupa iz palače Moise u Cresu u prostorije Laboratorija za konstrukcije Građevinskog fakulteta u Rijeci (Slika 4.), gdje je provedeno ispitivanje dana 31. kolovoza 2017. godine.

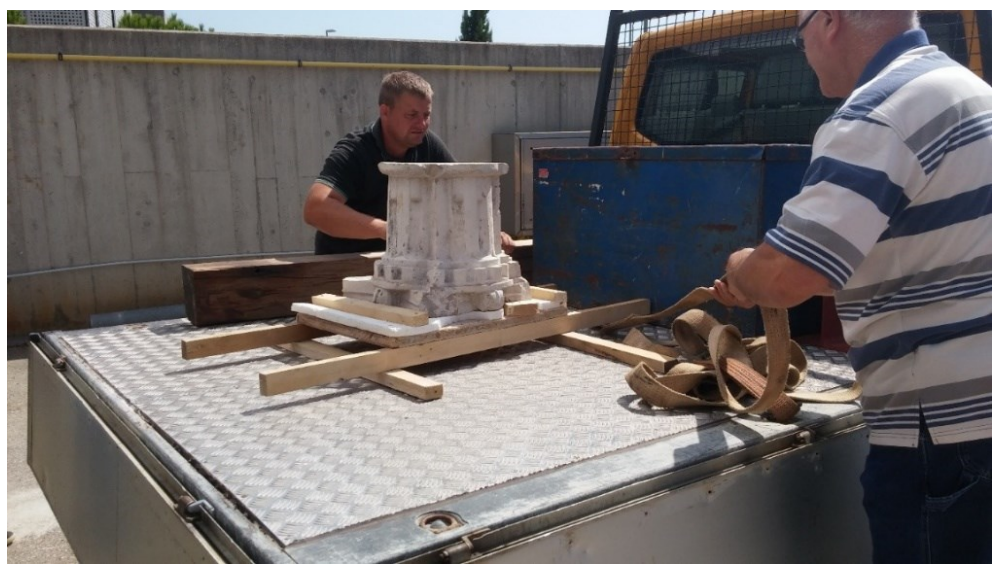

Slika 4. Transport kapitela stupa

Ispitivanje je provedeno na kidalici kapaciteta $600 \mathrm{kN}$, a korištena je i oprema za mjerenje pomaka s pripadajućim LVDT-om. Guma debljine 10 mm iznad i ispod kapitela stupa korištena je da bi se umanjila koncentracija naprezanja na kapitelu stupa (Slika 5.). Tlačno ispitivanje kapitela stupa provedeno je uz kontrolu sile brzinom od $5 \mathrm{kN} / \mathrm{min}$. S ovim postavkama ispitivanje bi trajalo 10 minuta. Predopterećenje je iznosilo $1 \mathrm{kN}$, što znači 
da se dijagram sila-pomak počinje crtati tek od $1 \mathrm{kN}$. Kriteriji za zaustavljanje ispitivanja su dostizanje maksimalne sile od $50 \mathrm{kN}$ ili početak širenja postojeće pukotine u kapitelu stupa.

Tlačno ispitivanja je prekinuto kada je na mjernoj ćeliji očitana sila od 50 kN. Nije došlo do širenja postojećih pukotina pa se je tlačno ispitivanje moglo provesti do tražene vrijednosti sile od $50 \mathrm{kN}$. Na kidalici su mjerene tri veličine: sila na mjernoj ćeliji, pomak pomične grede i vrijeme ispitivanja.

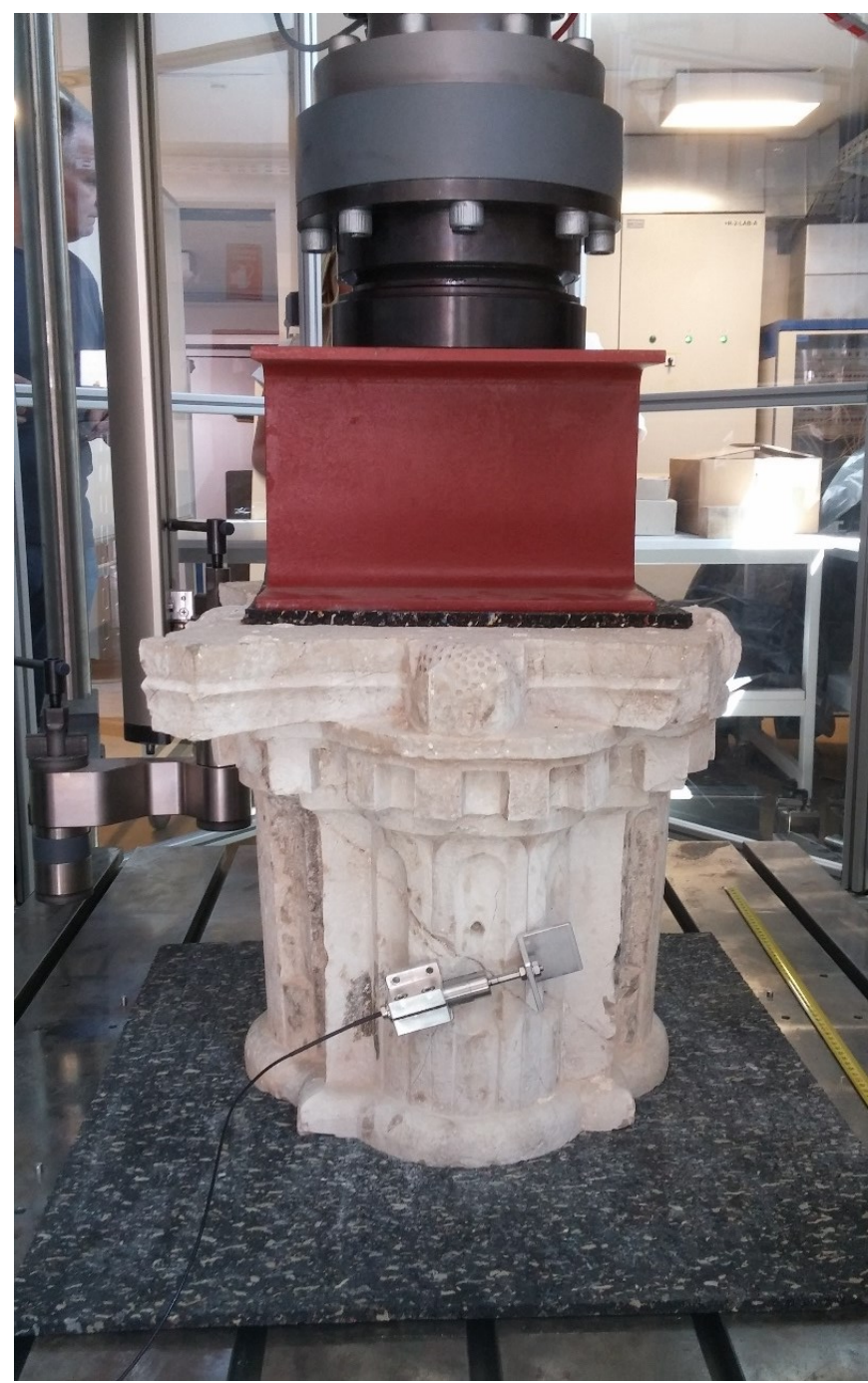

Slika 5. Kapitel stupa u kidalici 
Pomoću opreme za mjerenje pomaka i LVDT-a kontinuirano se pratio relativni pomak preko pukotine (Slika 5.). U slučaju da je došlo do širenja pukotine, odnosno povećanja relativnog pomaka izmjerenog preko LVDTa, prekinulo bi se ispitivanje. Osim toga, širenja pukotine pratilo se i vizualno.

Osim LVDT-a koji smo postavili preko postojeće pukotine, moguće je postaviti dodatne LVDT-e u vertikalnom smjeru na kapitelu stupa kako bi dobili vertikalni pomak kapitela stupa. S takvim postavljanjem LVDT-a naknadno bi bilo moguće odrediti Poissonov koeficijent kamena kapitela stupa. U ovom slučaju oni su izostavljeni budući da cilj istraživanja nije bio dobiti mehaničke karakteristike kamena jer bi u tom slučaju kapitel bilo potrebno opteretiti znatno većim silama od $50 \mathrm{kN}$.

\section{Rezultati ispitivanja}

Prikaz ovisnosti sile na mjernoj ćeliji kidalice i pomaka pomične grede kidalice prikazan je na Slici 6. Pri maksimalnoj sili od $49.99 \mathrm{kN}$ registriran je pomak pomične grede od $4,66 \mathrm{~mm}$. Ovako veliki pomaci posljedica su pomaka pomične grede kidalice koji uključuje pomake svih materijala koji su između gornje tlačne ploče i donje nepomične grede kidalice. Najveći utjecaj na ovako velike pomake ima guma zbog jako malog modula elastičnosti u usporedbi s modulima elastičnosti kamenog kapitela stupa i čelične ploče i I-profila.

Ovisnost pomaka na LVDT-u i vremena ispitivanja prikazana je na Slici 7. Maksimalni pomak na LVDT-u iznosi 0,00163 mm. Na Slici 7. vidljivo je da pomak na LVDT-u kontinuirano raste tokom vremena, i da nema naglog povećanja pomaka koji bi značio da je došlo do nekontroliranog povećanja širine postojeće pukotine na kapitelu stupa. Kontinuirano povećanje pomaka na LVDT-u posljedica je elastične deformacije kapitela stupa u smjeru postavljenog LVDT-a zbog Poissonovog koeficijenta kamena.

Pri sili od $50 \mathrm{kN}$ ne dolazi do nekontroliranog širenja postojeće pukotine na kapitelu stupa, što znači da kapitel može biti opterećen do veličine uporabnog opterećenja od $50 \mathrm{kN}$ (Slika 6.). 


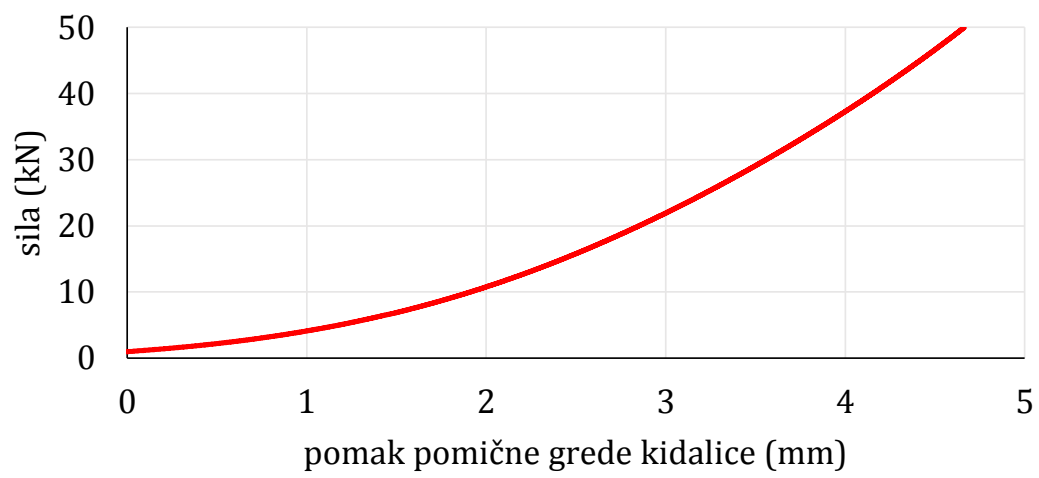

Slika 6. Dijagram sila - pomak pomične grede kidalice

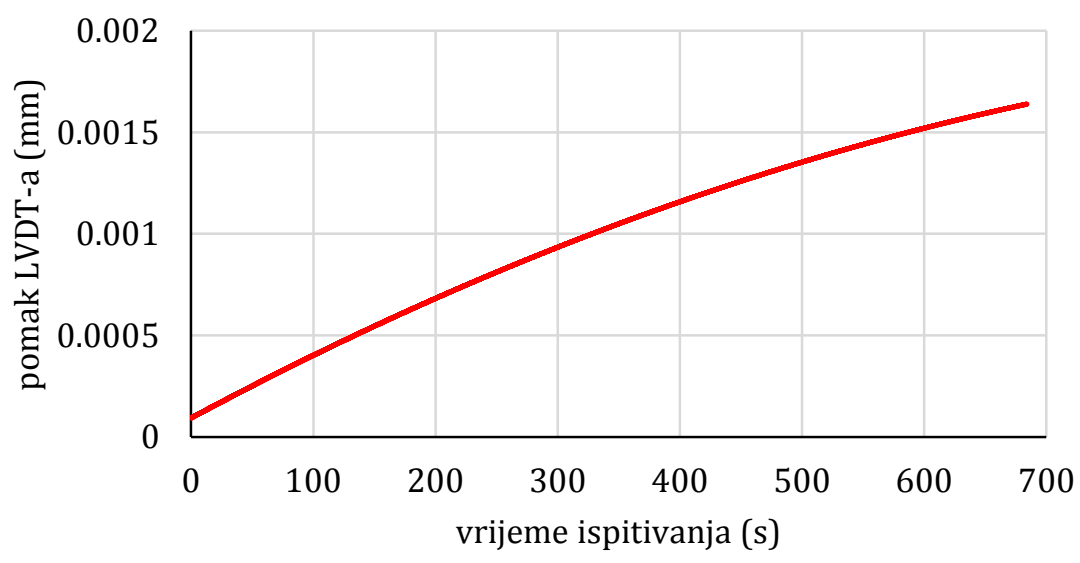

Slika 7. Dijagram pomak LVDT-a - vrijeme ispitivanja

\section{Kapitel stupa poslije ispitivanja}

Nakon uspješno provedenog laboratorijskog tlačnog ispitivanja kapitela stupa moglo se pristupiti ugradnji kapitela stupa. Na Slici 8. prikazan je ugrađeni kapitel stupa i dio konstrukcije koji se oslanja na kapitel stupa. 

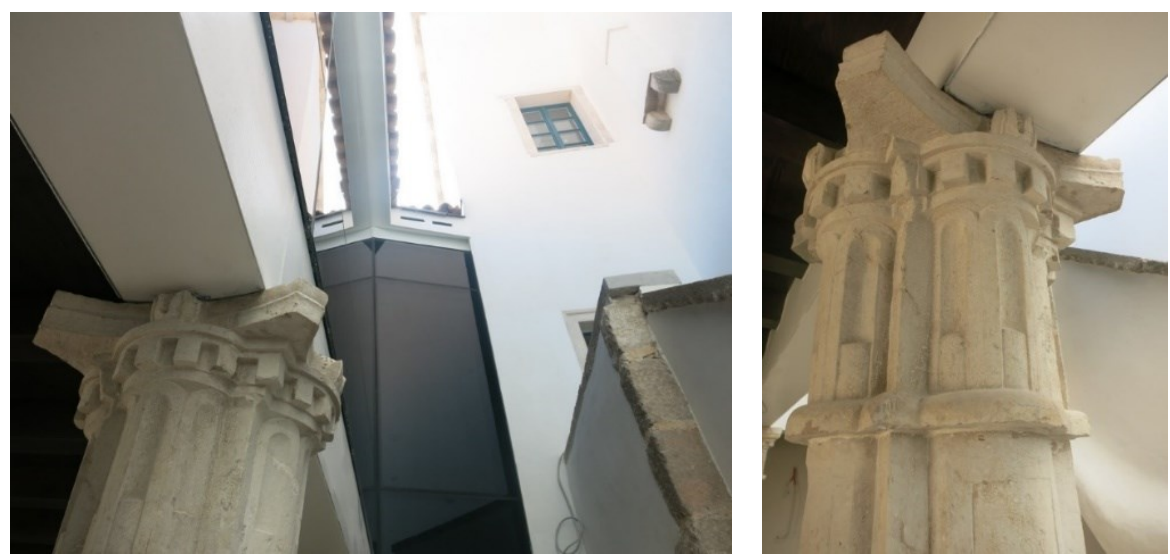

Slika 8. Kapitel stupa nakon sanacije [10]

\section{Zaključak}

Zbog oštećenja i pukotina na kapitelu stupa iz palače Moise u Cresu trebalo je provesti tlačno ispitivanje kapitela stupa do veličine uporabnog opterećenja. Iz rezultata laboratorijskog ispitivanja zaključili smo da se radi samo o površinskoj pukotini te da kapitel stupa može podnijeti predviđeno uporabno opterećenja od $50 \mathrm{kN}$.

U radu smo se zadržali samo na opisu eksperimentalnog tlačnog ispitivanja kapitela stupa bez dubljeg ulaska u problematiku nastanka oštećenja i pukotina na kapitelu stupa. Sanacije tradicijskih stupova zahtijevaju multidisciplinarni pristup iz potpuno različitih grana znanosti, uz uključivanje stručnjaka iz područja građevinarstva, arhitekture i konzervatora.

Teško je očekivati da pojedina struka može primjereno riješiti problematiku sanacije tradicijskih stupova. Problemi oštećenja tradicijskih stupova i spojeva su kompleksni, a za otkrivanje uzroka nastajanja i otvaranja pukotina potrebna bi bila detaljna nelinearna numerička analiza. Nelinearnost proizlazi iz materijalne nelinearnosti kamenog materijala stupova i kapitela, kao i nelinearnosti spoja stup-kapitel koji može prenositi samo tlačna naprezanja (sile). Rezultati dobiveni detaljnom nelinearnom numeričkom analizom bili bi osnova za ispravno pristupanje sanaciji tradicijskih stupova.

Zahvala. Ovaj je članak rezultat rada u okviru projekta Razvoj istraživačke infrastrukture na Kampusu Sveučilišta u Rijeci (RC.2.2.06-0001) koji je sufinanciran iz Europskog fonda za regionalni razvoj (EFRR) $i$ Ministarstva znanosti, obrazovanja i sporta RH. Rad je dio projekta 
"Poboljšanje proračunskih modela za ocjenu stanja građevinskih konstrukcija" (uniri-tehnic-18-127) koji financira Sveučilište u Rijeci.

\section{Literatura}

[1] Atalić, J., Uroš, M., Šavor, M. (2012) Utjecaj kontaktnih naprezanja na tradicijski kameni stup. Građevinar, 11/2012/64, str. 891-903.

[2] Lokošek, E., Kleiner, I. (2004) Zamjena kamenih stupova u prizemlju dvorca Veliki Tabor. Građevinar, 5/2004/56, str. 267-276.

[3] Lazarević, D., Dvornik, J., Fresl, K. (2004) Analiza oštećenja atrija Kneževa dvora u Dubrovniku. Građevinar, 10/2004/56, str. 601-612.

[4] Sušanj Protić, T. (2014) Renesansna kuća Moise u Cresu - rezultati konzervatorskih istraživanja 2011. godine, Ars Adriatica, 4/2014/, str. 283298.

[5] Cuculić, M., Mrakovčić, S., Jagodnik, V., Smolčić, Ž., Travaš, V. (2016) Potencijali istraživačkog rada na Građevinskom fakultetu u Rijeci. U: Lakušić, S., ur. ZAJEDNIČKE TEME - Sabor hrvatskih graditelja 2016. Cavtat: HSGI, str. 953962.

[6] http://www.novilist.hr. http://www.novilist.hr/Vijesti/Regija/Otoci/Novoruho-creske-ljepotice-Na-jesen-krecu-prvi-cjelozivotni-programi (21.7.2018.)

[7] http://www.ni.com/pdf/manuals/372581c.pdf (19.10.2018.)

[8] Nyce, D. S. (2016) Position Sensors. New Jersey: John Wiley and Sons.

[9] http://www.ni.com/labview/signalexpress/ (19.10.2018.)

[10] https://www.ing-grad.hr/hr/projekti/povijesne-zgrade-i-sakralnaarhitektura/tvrdjave-dvorci-palace1/1179-palaca-moise-cres (19.10.2018.) 